\title{
Virtual Reality-based Training for the Motor Development of People With Intellectual and Multiple Disabilities
}

\author{
Treinamento baseado em Realidade Virtual para o Desenvolvimento Motor de Pessoas \\ com Deficiência Intelectual e Múltipla
}

Rian Dutra da Cunha ${ }^{1}$, Frâncila Weidt Neiva², Rodrigo Luis de Souza da Silva ${ }^{1 *}$

\begin{abstract}
This study investigated the potential of using a virtual reality-based motor coordination and cognitive training for people with intellectual and multiple disabilities, focusing on their autonomy and community participation. A low-cost innovative interaction interface between the user and the virtual environment was proposed to provide a more realistic and intuitive interaction experience. Nine people with disabilities were selected from an institutional care for people with disabilities and they were enrolled in a four-week experiment, which consisted in going through three challenges. The results show that the patients demonstrated statistically significant improvements regarding the task gave, also based on the observational analysis of the instructor and physiotherapist. Thus, the analysis indicates that the VR-based method can be effective in the motor development of those patients, improving their autonomy and cognitive skills.

Keywords: Virtual Reality — Intellectual Disabilities — Multiple Disabilities

Resumo: Este estudo investigou o potencial da utilização de treinamento baseado em Realidade Virtual $(\mathrm{RV})$ para coordenação motora e cognitiva de pessoas com deficiência intelectual e múltipla, focando em sua autonomia e participação comunitária. Uma interface de interação inovadora e de baixo custo entre o usuário e o ambiente virtual foi proposta para fornecer uma experiência de interação mais realista e intuitiva. Nove pessoas com deficiência foram selecionadas a partir de uma instituição especializada em pessoas com deficiência e foram inscritas em um experimento de quatro semanas, que consistiu em passar por três desafios. Os resultados, com base na análise observacional do instrutor e fisioterapeuta, mostraram que os pacientes demonstraram melhorias estatisticamente significativas em relação às tarefas dadas. Assim, a análise indica que o método baseado em RV pode ser efetivo no desenvolvimento motor desses pacientes, melhorando sua autonomia e habilidades cognitivas.

Palavras-Chave: Realidade Virtual — Deficiência Intelectual — Deficiência Múltipla

${ }^{1}$ Computer Science Department, Federal University of Juiz de Fora, Brazil

${ }^{2}$ Informatics Postgraduate Program, Federal University of Rio de Janeiro, Brazil

*Corresponding author: rodrigoluis@gmail.com

DOI: http://dx.doi.org/10.22456/2175-2745.86478 • Received: 06/09/2018 • Accepted: 26/09/2019

CC BY-NC-ND 4.0 - This work is licensed under a Creative Commons Attribution-NonCommercial-NoDerivatives 4.0 International License.
\end{abstract}

\section{Introduction}

The traditional cognitive treatment allied to virtual realitybased methods is able to offer an effective, safe and interactive approach to the treatment of people with disabilities. For that reason, the current study discusses the contribution of virtual reality to improve the motor skills, making people with intellectual and multiple disabilities more autonomous and able to do daily common tasks, thus promoting social inclusion and improving their community participation through a motor and cognitive skills training.

The definition of social inclusion presented in [1] refers to being accepted as an individual beyond disability, focusing on two domains: interpersonal relationships and community participation. In this context, community participation is the involvement in community activities that promote the development of interpersonal relationships, including leisure activities, political and civic activities or organizations, productive activities, like employment or education, religious and cultural activities and groups and consumption, or access to goods and services, which the current study is focused on.

Virtual Reality (VR) is increasingly being recognized as an effective tool for the rehabilitation of cognitive processes and functional abilities. The VR-cognitive rehabilitation framework was first proposed in [2], for children with attention-deficit activity disorder (ADHD). Traditional treat- 
ment requires specific exercises to improve the cognitive and motor skills through repetitive training. Intense repetition of tasks is necessary to reorganize the brain in a particular area of understanding; however, it requires immense demands both on the patient and the professional [3]. In particular, because people with intellectual and multiple disabilities are difficult to engage, cognitive treatment approach applied to them can be a hard and complex task. Virtual reality-based methods, specially when it is game-like activities, are able to make cognitive and motor coordination treatment and rehabilitation more accessible to people with disabilities through their capacity to maintain their attention, providing an effective and safe training and educational media for those people.

As concluded in a recent systematic review presented in [4], there is huge lack of researches that investigate VR in treatment of other intellectual disabilities, as well as motor coordination disabilities.

In this paper, we verify the effectiveness and feasibility of virtual reality as a tool to support the motor and cognitive coordination development of people with intellectual and multiple disabilities, focusing on the community participation, from a VR-based training, monitoring the results and analyzing them from a quantitative and qualitative perspective. In Section 2, we describe the characteristics of the intellectual and multiple disabilities. In Section 3, we present related studies that investigated VR in the treatment of people with disabilities. In Section 3.2, we present the VR-DAD system developed in this study and its features. Section 4 describes our hypotheses, the details about this study as well as the procedure of the experiments. In Section 5 we present the results and in Section 6 our conclusions about this study.

\section{Intellectual and Multiple Disabilities}

As stated in [5], intellectual disability is a developmental disability characterized by limitations in intellectual functioning and adaptive behavior, resulting in the need for extraordinary supports for a person to participate in activities involved with typical human functioning.

Another term commonly related to intellectual disability is multiple disabilities, which refers to individuals with severe disabilities, such as a sensory disability associated with a motor disability. People with multiple disabilities commonly presents more than one significant disability related to physical mobility, speech, learning, visual, hearing and brain injury. Moreover, those individuals can also exhibit sensory losses and behavior and/or social problems.

Hence, intellectual disability is a state of functioning in which impairments to the central nervous system (CNS) (i.e., body functions and structures) result in activity limitations and participation restrictions, and, depending on the definition, a severe intellectual disability may be included in the term "multiple disabilities". Intellectual functioning is a type of human functioning, and is defined in the American Association on Intellectual and Developmental Disabilities (AAIDD) Manual on Definition, Classification and Support Systems in
Mental Retardation [5] as referring to a general mental ability that includes reasoning, planning, problem solving, abstract thinking, comprehending complex ideas, learning quickly and learning from experience.

\section{Related Studies}

Since computer technologies emerged in our society, many researches have been conducted to investigate the effectiveness of computer-based treatment of people with disabilities. Early studies, for instance $[6,7]$, suggested that using interactive computer software could encourage language use in children with disabilities. In 1973, Kenneth Mark Colby presented in [6] a system which consisted of a television-like screen and a typewriter-like keyboard in front of which a child sits. In the experiment, children could interact pressing the keys and symbols appeared on the screen accompanied by sounds of human voices and common noises. V. Bernard-Opitz said in [8] children with Autism is more enthusiastic when working with computers than in a "regular toy situation".

With the virtual reality technology more advanced and affordable, in 1991, McLellan said in [9] that virtual worlds, unlike real worlds, can be manipulated to make a task easier for the user. In 1995, Melissa Salem Darrow presented in [10] a summary of VR applications developed for people with disabilities, and discussed about the positive predictions for VR as an assistive technology for people with sensory, physical and emotional impairments. Authors in [11] said virtual environments are an effective and safe training and educational media for people with learning disabilities and suggests further researches to understand their full potentials. Also, they said that participants in a VR-based experiments can make as many mistakes as they wish without suffering the real or dangerous consequences of their errors, which is substantially important in this line of research. Dorothy Strickland, in [12] recommended using virtual reality in the treatment of people with Autism, which offers the potential to regulate a virtual environment to better match the needs of people with Autism Spectrum Disorder (ASD).

Virtual reality may offer a variety of possibilities within rehabilitation, including the potential to objectively measure behavior in challenging but safe, ecologically valid environments while maintaining experimental control over stimulus delivery and measurement [13]. The virtual reality system presented in [14] was used to teach people with learning disabilities to prepare food. The authors said the VR-based method was more beneficial than real training with workbook.

In [15] the authors presented a system aimed to promote a "pretend play" for children with ASD, which is related to imagination and cognition abilities, through the use of virtual reality tools. The results presented by the authors showed a significant advance in pretend play abilities after the intervention period.

The [16] study evaluated a novel intervention that combined VR with traditional cognitive rehabilitation methods to address impairments in contextual processing of objects 
in children with ASD. Several tasks were done in relation to the positioning of the objects, for instance whether a object is in the same direction of another one. According to the authors, all participants demonstrated statistical improvements in overall contextual processing ability and improvements in cognitive exibility.

The virtual dolphinarium presented in [17] allows children with ASD to act as dolphin trainers, focusing on improving their functional development learning and behavior. Authors concluded that VR is effective in the treatment of people with intellectual and multiple disabilities. Authors in [18] also stated that virtual reality is a promising tool for improving social skills, cognition, and functioning in autism, after a training intervention done with eight people with Autism. In [19], the feasibility of a virtual reality job interview training was evaluated with adults with Autism. Authors conclude that it is an accessible strategy for improving community-based outcomes among people with ASD, and stated VR-based training can be an effective tool to improve job interview skills for those individuals.

A virtual reality for vocational rehabilitation system for people with disabilities is presented in [20]. The authors said VR enables safe immersion of potential employees in a range of scenarios they may encounter before in a real job. Strickland at al [12] stated that virtual reality offers the potential to regulate an artificial computer environment to better match the expectations and needs of individuals with Autism, describing a study that focused on the use of VR as a learning aid with an immersive headset system.

In [21], the use of VR was applied to support children with ASD to learn vocabulary. They generated evidences about the improvement of the learning process that allows children to retain vocabulary items at the end of weeks.

There is a wide range of possibilities regarding the use of virtual reality to promote the community participation of people with intellectual disabilities. Although the articles described in this section have strongly contributed to the development of the academic scenario of Virtual Reality focused on rehabilitation, they have tended to focus on technical aspects and the technology itself, leaving aside human aspects and a sharper and more objective analysis about the real benefits provided by RV for people with intellectual and multiple disabilities. In our work we aimed to design a system focused on human development and community participation, whereas developing an easily replicable and scalable system. Therefore, we present an effective and low-cost system to support motor and cognitive development of people with intellectual and multiple disabilities, which provides safe training in a controlled environment through game-based playful activities.

\subsection{Ideation}

In order to propose a solution to support the improvement of motor and cognitive skills of people with intellectual and multiple disabilities, we engaged in a collaborative process with a non-profit organization that is dedicated to defending rights and providing services to people with intellectual and multiple disabilities. Being responsible for the social inclusion at several levels, the organization stands out for its pioneering and capillarity serving about 250.000 people with intellectual and multiple disabilities on a daily basis. During one year, in conjunction with the physiotherapists and other professionals of the organization, we followed the practices of work used to treat the patients. To understand the work practices, we performed observations, interviews, brainstorming sessions and walkthroughs.

Regarding activities to treat motor coordination, the organization provides equine therapy to improve coordination as a whole. With horses, the whole body is worked, both body balance and fine movements. The organization provides other manual activities besides equine therapy to improve coordination, for example, carpentry activities. Despite the use of some activities, the professionals of the organization did not have formal metrics to assess the patients performance and progression. The only point informally observed was the patient's ability to extend his arms (to open, lift, stretch the arms). Besides, they did not measure or run any specific tests to evaluate the evolution of patients. The evaluation was only subjective, based for example, on the feedback that the quality of patients' life has improved (ex: after a certain time of treatment, the patient can take the fork alone).

Regarding this scenario and perceiving the opportunities of improvement, we defined a target for the artifact design. The artifact should train the mainly logical reasoning, spatial perspective and motor coordination. The artifact would focus in the support of the traditional work practices, providing a systematized, safe (since they are not able to take the patients to real world scenarios for training different skills), controlled (adding the possibility of analyzing the later results) and gamified environment, which greatly increases the interest and engagement of patients, who are often dispersed.

\subsection{Proposed Solution}

A system called VR-DAD (Virtual Reality-Based Daily Activities Development) was developed for this study. The system makes use of immersive virtual reality to provide a virtual environment to improve the motor coordination abilities of people with intellectual and multiple disabilities, offering the possibility for individuals to improve their skills and to be more autonomous. The development of this system depended on other areas such as physiotherapy and pedagogy, and it was accompanied by specialists of these areas, as well as design and computer science. The prototype presented in this article, provides the following advantages over other systems (Section $3)$ :

- Low cost. It is not required any desktop computer nor extra device, such as movement and depth sensors. It is functional from a mid-range smartphone and simple virtual reality glasses (e.g., Google Cardboard); 
- Hand-based manipulation using augmented reality in a virtual reality environment, providing a more realistic and intuitive interaction;

- Auto leveling system, which fits the difficulty level to each individual according to his or her performance;

- Results-Based Monitoring. Through an online dashboard, which can be accessed on any internet browser, it is possible to monitor the results according to the activities metrics.

\subsection{Design and 3D Environment}

Our purpose for this project was not to create a realistic scenario, which would use real-time illumination, rendering shadows and high resolution textures. Realistic graphics would require a robust processing and it would not be possible to play it on mid-range smartphones, making the adoption of the proposed solution more expensive and therefore limiting its adoption by socio-economically vulnerable communities as well as government institutions with budget constraints.

Although the scenario was not much realistic, the project was designed to provide a real-world experience, and the immersion and the hand-based interaction were capable to offer that sensation to the participants. The 3D modeling was made using the software Autodesk Maya 2017 and the textures are a mix of digital painting and real pictures, using the software Adobe Photoshop CC.

\subsection{Hand-Based Interaction}

One of the innovative resources which offer advantages over the systems presented in Section 3 is the hand-based interaction. To provide a real-world experience, specially considering the cognitive and motor impairments of the participants, an interaction performed with their own hand (e.g., grab products, get money) is easier, more intuitive and effective.

The hand-based interaction is made by augmented reality into the virtual reality environment. The smartphone is placed in the VR head-mounted display and the system uses its camera to recognize the augmented reality marker, which is located over the hand of the participant (Figure 1). By the real-time recognition, the system replaces the marker with a virtual hand and the individual is capable to handle 3D objects in the VR scenario. For instance, if patients puts the hand over a product, it is outlined, and if he or she keeps the hand over it during three seconds, the product is selected (if the product is in the shopping list). Thus this specific task trains both the movement precision and the arm extension.

\subsection{Results-Based Monitoring}

By accessing the VR-DAD online dashboard, via any internet browser, it is possible to monitor the results according to the activities metrics. At the beginning of each session game, the feedback system starts to get relevant data related to the patient performance. Lastly, at the end of the game, the result is sent to the VR-DAD online system, described in Section
3.6. Thus, from the data collected by the system, specialists are able to analyze the cognitive and motor improvement of the patients and make more precise decisions regarding their treatment.

In this project, participants should go through three challenges, with different tasks and motor skills to be trained (Section 4). Based on those tasks, the metrics proposed in this version of the VR-DAD system are: how many fruits were collected, how many rats were hit, how many butterflies were grabbed, how many times participant touches the bridge wall, failed fruit selection attempts, attempts to select wrong fruits, failed butterfly selection attempts, failed attempts to hit rats. Figure 2 shows an example of the results dashboard.

\subsection{Case Study}

In this project, the virtual environment represents a fantasy scenario, where the participants had to go from a platform to the last one, crossing bridges over an ocean, and in each platform they had to go through challenges, which is fully described in Section 4. It was developed using the Unity 5.4 game engine, in which the Vuforia $S D K$ was added. The Vuforia $S D K$ is an augmented reality software development kit for mobile devices that allows the creation of augmented reality applications. It uses computer vision technology to recognize image targets in real-time, and in this project it was used to track the hand of the participants, who used an augmented reality target attached to their hands (Figure 1).

During each game, specific data are saved to be used as parameters in the monitoring module (Section 3.5). Lastly, at the end of the game, the system exports the data (JSON format) to the online API, which handles the data and save it to the online system.

\section{Materials and Methods}

\subsection{Research Questions}

The research question of this study are: (1) How virtual reality technology can provide a systematic immersive environment for people with intellectual and multiple disabilities for making them more autonomous, regarding the primary body and arms skills? (2) How to use computation to develop assistive tools to improve motor and cognitive skills of people with intellectual disabilities?

Based on these questions, the following hypotheses were formulated:

- Hypothesis 1 (H1): virtual reality can support the cognitive development, also improving the autonomous capabilities of people with intellectual and multiple disabilities;

- Hypothesis 2 (H2): hand-based interaction in a VR game-like activity can provide a natural, attractive and intuitive interaction, thus having the potential to be effective both for the cognitive and the motor coordination development. 


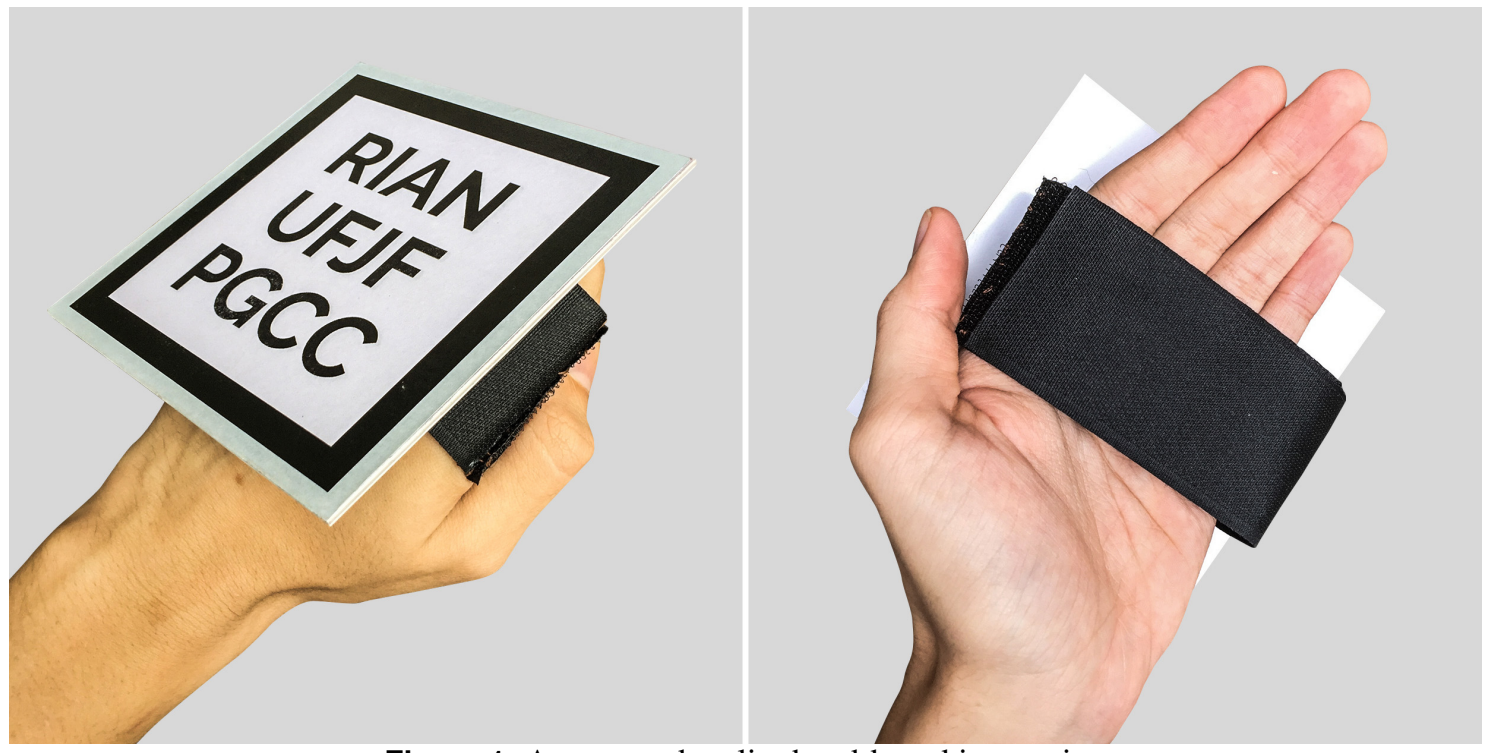

Figure 1. Augmented reality hand-based interaction

\subsection{Experimental Design}

A single-subject design was used in the current study. Nine people with intellectual and multiple disabilities were enrolled in the study, which consisted of a four-week follow-up session, with outcomes assessed throughout.

\subsection{Participants}

For the case study, which was an illustrative case study done over four sections, 9 people with intellectual and multiple disabilities were selected from an institutional care for people with disabilities. They were selected under the ethical approval obtained from the ethics committee of the local university, as well as done with the consent of the responsible for the patients. The inclusion criteria were as follows: (1) diagnosis of multiple disabilities; (2) motor coordination nonsevere, that is, patient should be able to use his or her hand to do the task; (3) basic cognitive capability, that is, individual had to be aware of what should be done in the task; (4) chronological age greater than 18 .

\subsection{Equipment and Settings}

The experiments were conducted in the facilities of the institutional care for people with disabilities. The virtual reality application was tested in the smartphones Samsung Galaxy S3 (Android OS) and iPhone 6 Plus (iOS). During the sections, a Macbook Apple was used to mirror the smartphone screen, using an USB cable, thus the author and physiotherapist could see what the participant saw during the session. Regarding the virtual reality head-mounted display, a custom version of Beenoculus was used. Because the hand-based interaction is made by augmented reality (Section 3.4), the HMD Beenoculus had to be customized with a frontal cut, right over the smartphone camera, so it is able to register the image and so create the augmented reality experience.

Once our focus was on developing an easily scalable sys- tem (e.g., it can be build for other operating systems and devices, with large possibilities for creating new activities, other difficulty levels, etc.) and replicable (i.e., other researchers could propose improvements), our technical choices were based on these aspects. For instance, the Unity game engine was used due its popularity and ease of porting to various operating systems (e.g., iOS, Android), as well as being compatible with well-known languages (i.e., C\# and Javascript). As for the hardware, we decided not to use lineup of virtual reality headsets or any other VR devices (e.g. Oculus Rift, HTC Vive), because they usually require a high-level computer, cables and other peripherals that may hinder the movements during activities; instead, we opt to use only one mid-range smartphones, accessible to many people, not dependent on any other peripheral, and a low-cost virtual reality head-mounted display.

\subsection{Procedure}

In order to define an approach to develop the gross motor skills (i.e., arm and hand) for people with intellectual and multiple disabilities using assistive technology, a study case has been defined. The study case was placed in a fantasy scenario, which consisted of a task where the participants had to go from a platform to the last one, crossing bridges over an ocean, and in each platform they had to go through challenges: (1) collect fruits from the ground; (2) hit rats with a ball bazooka; (3) grab flying butterflies. Figure 3 shows the virtual environment and the augmented reality hand-based interaction, presenting screenshots of all three challenges. In each one of the challenges they had to get the highest score they could in a limited time. Also, to go from a platform to the next one, they were required to cross a bridge. In each one a penalty was counted every time the virtual body touches the bridge wall. Each participant run the task around 5 minutes. 
Evaluations

\section{Participant's name}

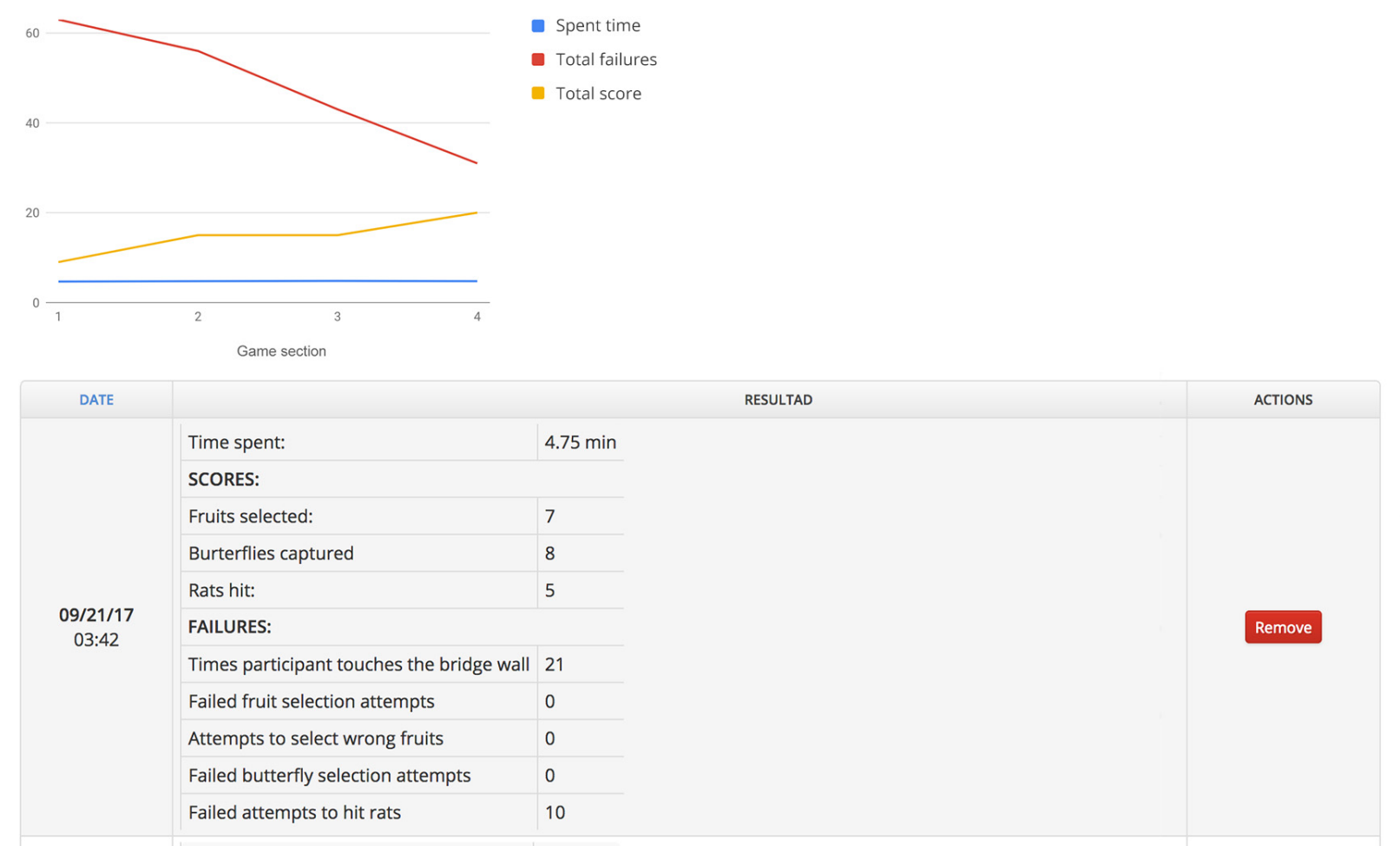

Figure 2. Example of the results dashboard (partial screen).

\subsubsection{System use demonstration}

Regarding the use of the virtual reality technology and the VR-DAD system itself, there was no need to apply a perform training phase, because the selected participants for the case study presented in this work had already participated in another virtual reality study using a similar system, a couple of months ago, which is discussed in study [22].

Nevertheless, as the VR-based task presented in this work is totally different from the previous one, an use demonstration was provided by one of the authors of this work. The author weared the virtual reality glasses, put the augmented reality marker over the hand and connected the smartphone to the laptop to mirror the application view, so participants could see everything the author was able to see during the use demonstration. Then, all the three challenges were presented and the tasks were explained, and all participants understood what they were requested to do.

\subsubsection{Four-Week Follow-up Session}

After the use demonstration, a section per week was done with each one of the selected patients (Figure 4). The experiment had the difficulty increased at every task. For instance, for the latest tasks the patients were requested to pick up fruits and butterflies located further away from them. Additionally, in each task the participants were more autonomous, that is, physiotherapist interfered less and less during the task. In the latest task, almost all the patients could do the task without any help.

At the end of the case study, the results were analyzed (Section 5) to verify if there was an improvement regarding the patients' performance. Besides that, the physiotherapist gave her conclusion according to her observation during the period of the experiments. After the experiments, she observed an improvement related to balance and gross motor skills, in this case, specific to movement and coordination of the arms (Section 5).

\section{Data Analysis and Results}

After the four-week follow-up session, we analyzed the results that were sent to the VR-DAD online system by the VR application, stored at the end of each participant's game. Overall, we were able to notice there was an improvement regarding the score obtained and the mistakes made, indicating the virtual reality-based method was effective in this study, as can be seen in Figure 5.

In the first game session, the mean score obtained by the selected patients was 7.111 and after the intervention, the participants presented a mean score obtained of 15 , as can be verified in Table 1, which describes mean, standard deviation 

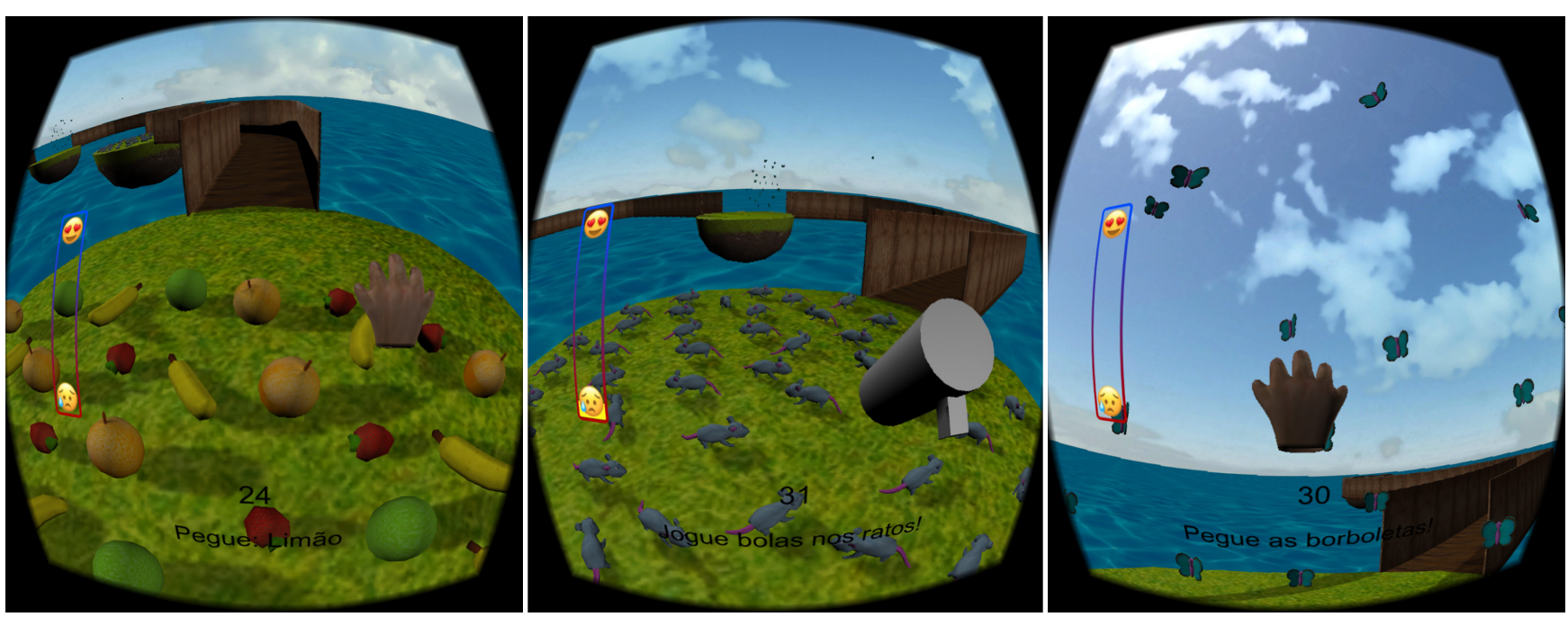

Figure 3. Challenges presented in the second case study. Participants should: 1) Collect fruits from the ground; 2) Hit rats with a ball bazooka; 3) Grab flying butterflies.

Table 1. This table shows the result related to score obtained by participants during the sessions of the case study.

\begin{tabular}{|l|c|c|c|c|}
\hline Game section & 1 & 2 & 3 & 4 \\
\hline Mean & 7.111 & 8.889 & 11.667 & 15.000 \\
\hline Standard deviation & 4.372 & 3.296 & 2.598 & 5.025 \\
\hline Margin of error & 2.397 & 1.807 & 1.424 & 2.755 \\
\hline
\end{tabular}

Table 2. This table shows the result related to mistakes made by participants during the sessions of the case study.

\begin{tabular}{|l|c|c|c|c|}
\hline Game section & 1 & 2 & 3 & 4 \\
\hline Mean & 78.778 & 68.667 & 53.000 & 46.333 \\
\hline Standard deviation & 20.774 & 12.787 & 9.247 & 12.349 \\
\hline Margin of error & 11.390 & 7.011 & 5.070 & 6.771 \\
\hline
\end{tabular}

and margin of error using a confidence interval of $90 \%$ in order to make this study feasible.

During four weeks, the patients were submitted to tasks available by the VR-based game. Thus, at the end of each game session, each participant obtained his or her game session result provided by the VR-DAD system. Table 2 shows the mean mistakes made over the four game sessions, as well as it presents standard deviation and margin of error using a confidence interval of $90 \%$. In order to make a more visible analysis, all mistakes were merged and counted, which are: times participant touches the bridge wall, failed fruit selection attempts, attempts to select wrong fruits, failed butterfly selection attempts and failed attempts to hit rats.

Based on the results, it is possible to notice the patients obtained higher scores over the tasks and made less mistakes, showing an improvement on the performance of the participants. They could select the correct fruits and butterflies faster, as well as they were able to guide their body better while they crossed the bridge and their hand and fist movement and precision were improved regarding the second task, which consisted in hit rats with a ball bazooka.

\subsection{Physiotherapist's feedback}

All the nine patients had their performance improved after the experiments, both motor coordination and in cognitive capabilities. Naturally, some participant had greater improvement than others. The physiotherapist also said it was perceived a gradual advance in the perception, the concentration and the elevation of the self-esteem of the selected patients. The experiment was aimed of improving the gross motor coordination of the participants, mainly focused on the extension of the patient's arms and the movement precision of their hands.

In addition to verifying an improvement in the results of the tasks (Section 5), the physiotherapist and the instructor said the participants' motor skills were slightly enhanced throughout the ordinary days.

Based on this study case, the hypothesis that virtual reality could support the motor coordination development, improving the autonomous capabilities of people with intellectual and multiple disabilities was ratified, proving virtual reality has real potential to support the treatment of people with intellectual and multiple disabilities. Regarding the second hypothesis that hand-based interaction in a VR game-like activity could provide a more natural, attractive and intuitive interaction, being more effective both for the cognitive and the motor coordination development, instead of using a joystick or another device for the virtual objects manipulation, it was based on the observational analysis of the professionals, who noticed a small improvement on their gross motor skills, such as arm extension and more precise movements. The results related to the mistakes made (Figure 5) also show they were more precise in the latest game sessions.

Lastly, over the tasks, sometimes the patients were requested to pick up fruits and butterflies located further away from them, which is harder to do. Thus, it was possible to observe they perform these tasks easier. 


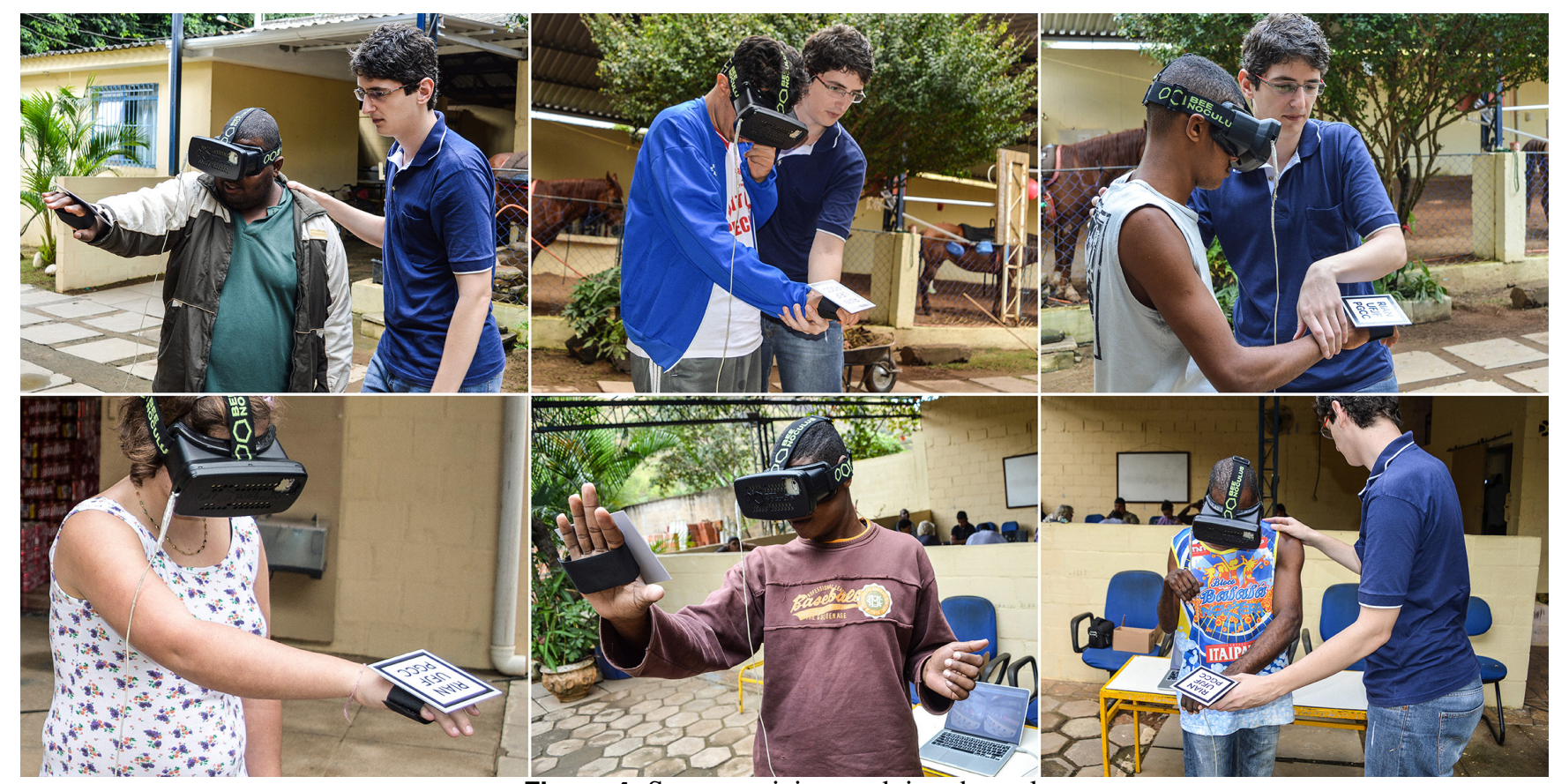

Figure 4. Some participants doing the task

\section{Conclusions and Future Works}

In this study, it was proposed a virtual reality-based method for motor coordination and cognitive treatment for people with intellectual and multiple disabilities. Also, a low-cost innovative interaction interface between the user and the virtual environment, provided by the VR system, was proposed to accomplish a more realistic and intuitive interaction during the requested tasks.

A system called VR-DAD (Virtual Reality-Based Daily Activities Development) was developed for this study, which uses immersive virtual reality to provide a virtual environment for teaching people with intellectual and multiple disabilities regarding to common daily activities, offering the possibility for individuals to improve their skills and to be more autonomous. A few advantages are offered by the VR-DAD system, such as: (i) Low cost, because it only requires a mid-range smartphone and simple virtual reality glasses; (ii) Hand-based manipulation; and (iii) Results-based monitoring through an online dashboard.

A case study was used in which nine patients with intellectual and multiple disabilities were selected and assigned to the VR-based tasks. The case study aimed to improve the patients' gross motor coordination of arms and hands, as well as their reflex and visual perception.

Although there are a few works that present VR systems focused on the treatment of people with intellectual disabilities, there is still huge lack of researches that deeply investigate VR in treatment of those individuals, including other cognitive and motor coordination impairments. Most of the studies focused on technical and technological aspects, and did not conduct expressive experiments with humans nor showed significant statistical results that could prove the effectiveness of VR on treatment of intellectual disabilities. Once our main concern was to develop a feasible VR system and to test it with a real sample of patients, we herewith present our methodology and statistical results that ratify our primary hypothesis.

The results of the experiments demonstrated the effectiveness and feasibility of using virtual reality technologies for the cognitive and motor coordination training of people with intellectual and multiple disabilities. The low-cost intuitive hand-based manipulation made the task more natural and easier to be performed, letting the participants more autonomous into the virtual environment, acting like in real world. Once the participants didn't have to learn how to use any devices (i.e., joysticks), they were able to focus on the provided task, indeed.

Overall, after the four-week follow-up sessions of the case study, the participants were able to obtain $110 \%$ more score and $41 \%$ less mistakes on average, which represents an effective improvement, considering the short period, demonstrating improvement of the overall cognitive functioning of individuals with intellectual and multiple disabilities. Also, it was noticed they were more confident and autonomous doing the task.

The improvement may be attributed to exercising attentional processes during the engagement of the virtual reality training. As stated in [23], the attentional processes are considered the basic component of cognitive function. The immersive and interactive nature of the VR-based method might offer an pleasurable experience for the participants, motivating them to further engage in the provided task.

Regarding this case study, we aimed to generate evidences 
Virtual Reality-based Training for the Motor Development of People With Intellectual and Multiple Disabilities
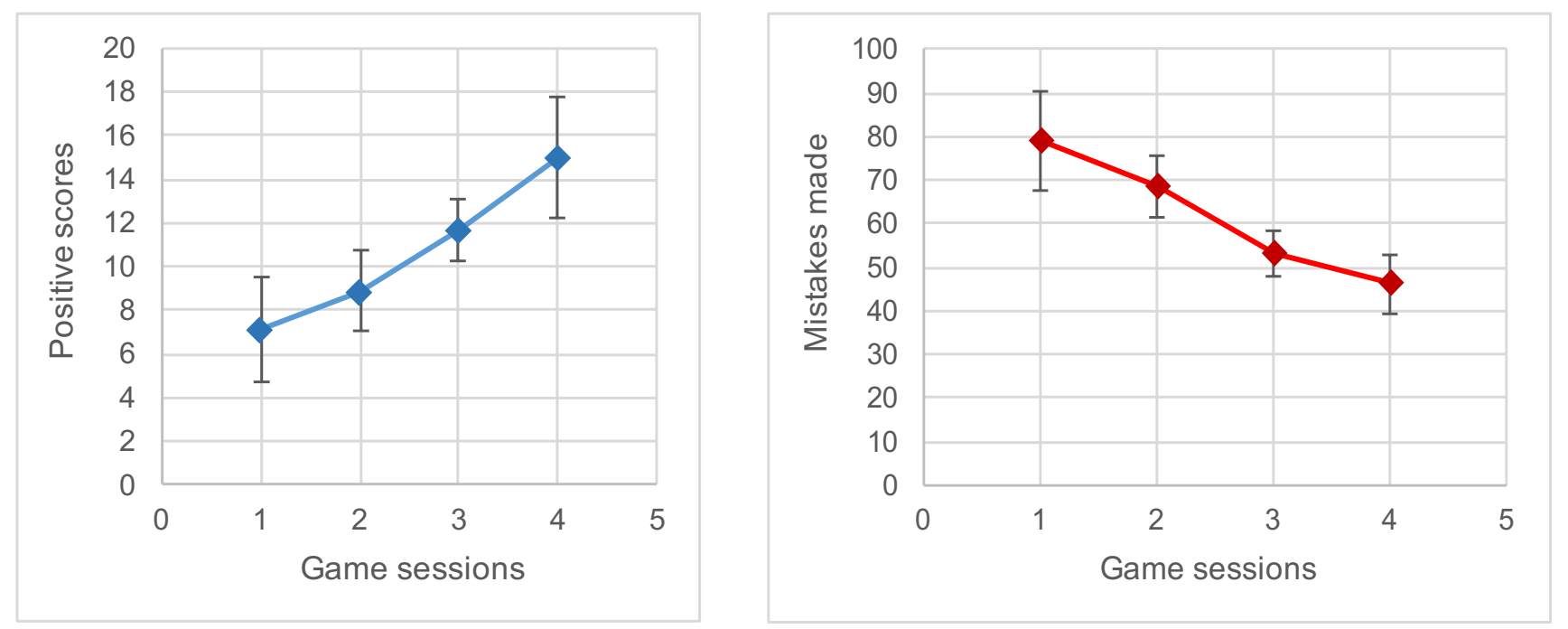

Figure 5. Game sessions result - Score obtained and mistakes made.

about the potential of the use of virtual reality-based task system to support the motor skills and cognitive development of people with intellectual and multiple disabilities, focusing on their autonomy and ability to do tasks by themselves, thus their community participation social inclusion.

Lastly, based on the analysis in Section 5 it was possible to prove that virtual reality-based method can be effective in the cognitive and motor skills development of people with intellectual disabilities.

\section{Author contributions}

Rian Dutra da Cunha - Main developer of this work. Frâncila Weidt Neiva - Data analysis and evaluation. Rodrigo Luis de Souza da Silva - Research Advisor.

\section{References}

[1] SIMPLICAN, S. C. et al. Defining social inclusion of people with intellectual and developmental disabilities: An ecological model of social networks and community participation. Research in developmental disabilities, Elsevier, v. 38, p. 18-29, 2015.

[2] RIZZO, A. A.; BUCKWALTER, J. G. Virtual reality and cognitive assessment. Virtual Reality in Neuro-PsychoPhysiology: Cognitive, Clinical and Methodological Issues in Assessment and Rehabilitation, v. 44, p. 123, 1997.

[3] BUTLER, R. W. Cognitive rehabilitation. In: HUNTER, S. J.; DONDERS, J. (Ed.). Pediatric Neuropsychological Intervention. [S.1.]: Cambridge University Press, 2007. p. 444-464.

[4] CUNHA, R. D. da; NEIVA, F. W.; SILVA, R. L. d. S. da. Virtual reality as a support tool for the treatment of people with intellectual and multiple disabilities: A systematic literature review. Revista de Informática Teórica e Aplicada, v. 25, n. 1, p. 67-81, 2018.

[5] SCHALOCK, R. L. et al. Intellectual disability: Definition, classification, and systems of supports. [S.1.]: ERIC, 2010.

[6] COLBY, K. M. The rationale for computer-based treatment of language difficulties in nonspeaking autistic children. Journal of Autism and Developmental Disorders, Springer, v. 3, n. 3, p. 254-260, 1973.

[7] GOLDENBERG, E. P. Special technology for special children. Baltimore: University Park Press, 1979.

[8] BERNARDOPITZ, V.; ROOS, K.; BLESCH, G. Computer-assisted instruction in autistic-children. Zeitschrift fur Kinder-Und Jugenpsychiatrie und Psychotherapie, VERLAG HANS HUBER LANGGASS-STRASSE 76, CH-3000 BERN 9, SWITZERLAND, v. 17, n. 3, p. 125-130, 1989.

[9] MCLELLAN, H. Virtual environments and situated learning. Multimedia Review, v. 2, n. 3, p. 30-37, 1991.

[10] DARROW, M. Virtual reality's increasing potential for meeting needs of persons with disabilities: What about cognitive impairments. Proceedings of the Third International Conference on Virtual Reality and Persons with Disabilities, 1995.

[11] CROMBY, J.; STANDEN, P. J.; BROWN, D. J. The potentials of virtual environments in the education and training of people with learning disabilities. Journal of Intellectual Disability Research, v. 40, n. 6, p. 489-501, 1996.

[12] STRICKLAND, D. Virtual reality for the treatment of autism. Studies in health technology and informatics, Ios Press, p. 81-86, 1997.

[13] SCHULTHEIS, M. T.; RIZZO, A. A. The application of virtual reality technology in rehabilitation. Rehabilitation 
psychology, Educational Publishing Foundation, v. 46, n. 3, p. 296, 2001.

[14] BROOKS, B. et al. An evaluation of the efficacy of training people with learning disabilities in a virtual environment. Disability and rehabilitation, Taylor \& Francis, v. 24, n. 11-12, p. 622-626, 2002.

[15] HERRERA, G. et al. Development of symbolic play through the use of virtual reality tools in children with autistic spectrum disorders: Two case studies. Autism, Sage Publications Sage UK: London, England, v. 12, n. 2, p. 143-157, 2008.

[16] WANG, M.; REID, D. Using the virtual reality-cognitive rehabilitation approach to improve contextual processing in children with autism. The Scientific World Journal, Hindawi Publishing Corporation, v. 2013, 2013.

[17] CAI, Y. et al. Design and development of a virtual dolphinarium for children with autism. IEEE transactions on neural systems and rehabilitation engineering, IEEE, v. 21, n. 2, p. 208-217, 2013.

[18] KANDALAFT, M. R. et al. Virtual reality social cognition training for young adults with high-functioning autism. Journal of autism and developmental disorders, Springer, v. 43, n. 1, p. 34-44, 2013.
[19] SMITH, M. J. et al. Virtual reality job interview training in adults with autism spectrum disorder. Journal of Autism and Developmental Disorders, Springer, v. 44, n. 10, p. 24502463, 2014.

[20] BOZGEYIKLI, L. et al. Vr4vr: Towards vocational rehabilitation of individuals with disabilities in immersive virtual reality environments. In: IEEE. Virtual and Augmented Assistive Technology (VAAT), 2014 2nd Workshop on. [S.1.], 2014. p. 29-34.

[21] KHOWAJA, K.; SALIM, S. S. Serious game for children with autism to learn vocabulary: An experimental evaluation. International Journal of Human-Computer Interaction, Taylor \& Francis, p. 1-26, 2018.

[22] CUNHA, R.; SILVA, R. L. d. S. da. Virtual reality as an assistive technology to support the cognitive development of people with intellectual and multiple disabilities. In: Brazilian Symposium on Computers in Education (Simpósio Brasileiro de Informática na Educação-SBIE). [S.1.: s.n.], 2017. v. 28, p. 987.

[23] BRENNER, H. D. et al. Treatment of cognitive dysfunctions and behavioral deficits in schizophrenia. Schizophrenia bulletin, National Institute of Mental Health, v. 18, n. 1, p. 21, 1992. 